\title{
A Review on Ground Water Quality Assessment of Akkalkuwa Region, Nandurbar (Maharashtra)
}

Shaikh Ibrahim", Seraj Alam², Margub Alam², Faisal Ahmad², Saiyad M Asif², Syed Sarfraz Shahid², Umarfarook H Momin ${ }^{3}$

${ }^{*}$ Assistant Professor, Department of Civil engineering Department, Jamia Institute of Engineering and Management Studies, Akkalkuwa, K.B.C. North Maharashtra University, Jalgaon, Maharashtra, India ${ }^{2}$ Department of Civil Engineering, Jamia Institute of Engineering and Management Studies, Akkalkuwa, K.B.C. North Maharashtra University, Maharashtra, India

${ }^{3}$ Shirish Patel and Associates Pvt Ltd, Mumbai, Maharashtra, India

\begin{abstract}
Due to increase population, advanced agricultural practices, industrialization, man-made activity, water is being highly polluted with different contaminants. Water is a vital resource for human survival. This research paper examines the quality of municipal corporation supplied water, bore-well, jamia filter plant and hand pump of akkalkuwa taluka of nandurbar maharshtra, India. Sample from five different places were collected in the month of march,2019. The physio-chemical and biological parameters was analyzed with reference to I.S/B.I. S and W.H.O. recommendation. During the study period various water quality parameters were analyzed $\mathrm{pH}$, Hardness, Conductivity, turbidity, Dissolved oxygen, Chemical oxygen demand, Alum dose, Total solids, Biological oxygen demand, Alkalinity, Residual chlorine. The present study concluded that the total solids and residual chlorine and BOD in water sample is above the permissible limit but total solids is above the acceptable limit and below the permissible limit, and remaining those parameters under the limits.
\end{abstract}

Keywords : Water Quality Assessment, Water Quality Index, Geographic Information System, W.H.O., BOD, pH, Hardness, Conductivity, Turbidity, Dissolved Oxygen, Chemical Oxygen

\section{INTRODUCTION}

Water is one of the most important and abundant compounds of the ecosystem. All living organisms on the earth need water for their survival and growth. As of now only earth is the planet having about $70 \%$ of water. But due to increased human population, industrialization, the use of fertilizers in the agriculture and man-made activity, it is highly polluted with different harmful contaminants. In Akkalkuwa and Nandurbar district Maharashtra state municipal supplied drinking water plays an important role as these district abundant increasing population growth. The main sources of ground water in akkalkuwa are tube-well, well, reservoir, bore well. Municipal supply water from the major source of water supply for drinking purposes in most part of India. In Akkalkuwa more than $90 \%$ of the population of Akkalkuwa region depend upon the natural ground water for their daily water demand. The safe portable water is absolutely essential for healthy living. According to WHO/IS above $80 \%$ of the diseases of the world population and more than 
one-third of the deaths in the developing countries are due to pollution of water.

An effort has been made to comprehend the groundwater quality of Akkalkuwa region for drinking purpose utilizing Water Quality Index (WQI) and Geographic Information System (GIS) techniques. In this study four groundwater samples were collected during March, 2019. Standard methods have been adopted in groundwater sampling which are prescribed by the American Public Health Association (APHA, 1995), and World Health Organisation (W.H.O). Eleven water quality parameters have been considered to ascertained water quality index. $\mathrm{pH}$, residual chlorine, turbidity, total solids, conductivity, alkalinity, hardness, biological oxygen demand, chemical oxygen demand, dissolved oxygen and alum dose. The World Health Organisation has been considered to assess the suitability of groundwater for drinking purposes. This study reveals that $66 \%$ area is falling under excellent and $14 \%$ very good and good category and $20 \%$ area is falling under poor, very poor and unfit category as per the W.H.O classification. The predicted accuracy of the obtained result is around $97.05 \%$ reflecting capability of adopted techniques. The present study is helpful in proper planning and management of available water resource for drinking purpose.

\section{LITERATURE REVIEW}

The various technical on the assessment of water quality for bore-well, municipal corporation, handpump and jamia filter plant and different areas have been standard research level for the study. The various physio-chemical para meter was studied and analysed in march, 2019 different parameters which is conducted or analysed like D.O, B.O.D, C.O.D, pH, Turbidity, Residual chlorine, Alkalinity etc. Where studied. The result revealed that there was significant seasonal variation in some physical-chemical property of water but hand-pump was moderately polluted in akkalkuwa region on the basis of study its was clarify that this water is not for potable and due to some pollutants organism it is harmful for skin and aquatic life.

We are referred various technical research papers on assessment of ground water quality for bore-wells, hand-pump, reservoir and different places, which are presented in phase one reported work on assessment of ground water quality which is summarized below. Physio-chemical parameters for testing of waters which is studied by SS Sager, RP Chavan, CL Patil, DN Shinde, SS Kekane, $8^{\text {th }}$ Oct 2015 and which is accepted in 10 $10^{\text {th }}$ Nov 2015.

Another review which is presented by dr. Seema Tiwari at Sagar institute of research and technology, Bhopal, India. 10 $0^{\text {th }}$ march 2015

Another review which Is published by Divya Bhardwaj and Neetu Verma which is M. TECH scholar and assistant professor of Deenbandhu Chooturam university, sonepat, Haryana.

We are also follow the procedure or safety and accuracy of municipal corporation of Nandurbar P.W.D division and we also follow the NRDWS Guidelines 2013, and national accreditation board for testing and calibration laboratory.

\subsection{Site Study: -}

The water of Reservoir, hand pump, and Filter water of akkalkuwa nandurbar Maharashtra is used by $90 \%$ of people which is survive in akkalkuwa region. The present study was conducted in akkalkuwa rural area the geographical coordinates of akkalkuwa nandurbar, India is latitude $21.55^{\circ} \mathrm{N}$ longitude $74.02^{\circ} \mathrm{E}$.

Elevation above sea level: $686 \mathrm{ft}$. (209meter) the state of Maharashtra is primarily a mountainous or hilly area. 


\subsection{Collection of Sample and Their Analysis}

The total one municipal supplied water sampling sites two samples from different two sampling site of akkalkuwa during the last February to half of the march in the year 2019. The water samples for analysis were collected in plastic bottles and all the sample were stored in sampling kits and brought to the Environment laboratory for detailed chemical and bacteriological analysis. The physio-chemical analysis was performed following standard method (I.S \&B.I. S).

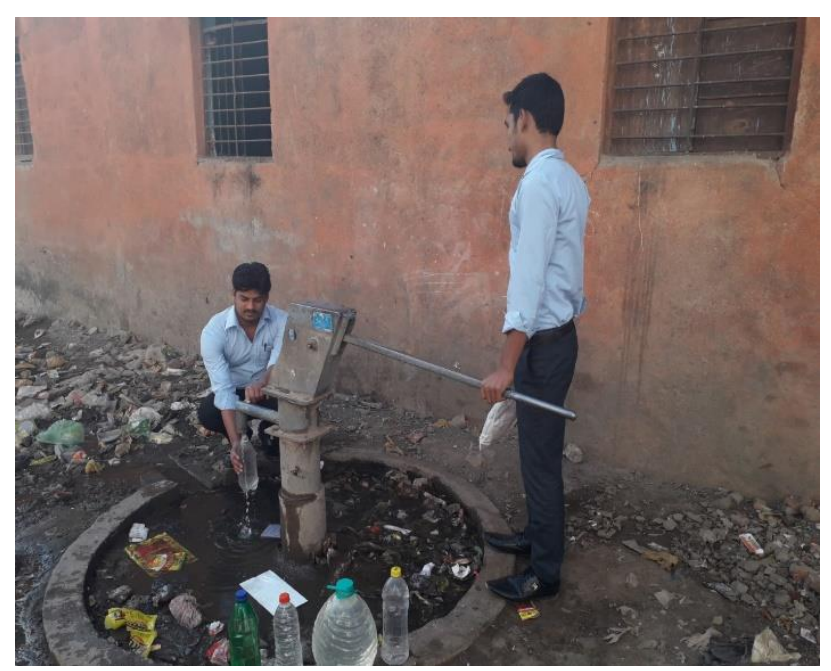

Fig-1. Hand pump Akkalkuwa

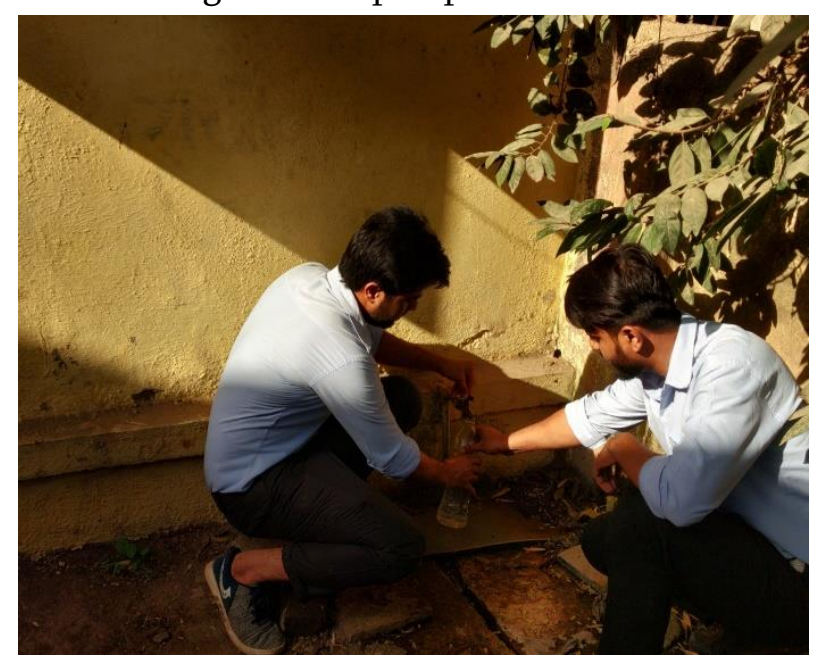

Fig-2. Reservoir Akkalkuwa

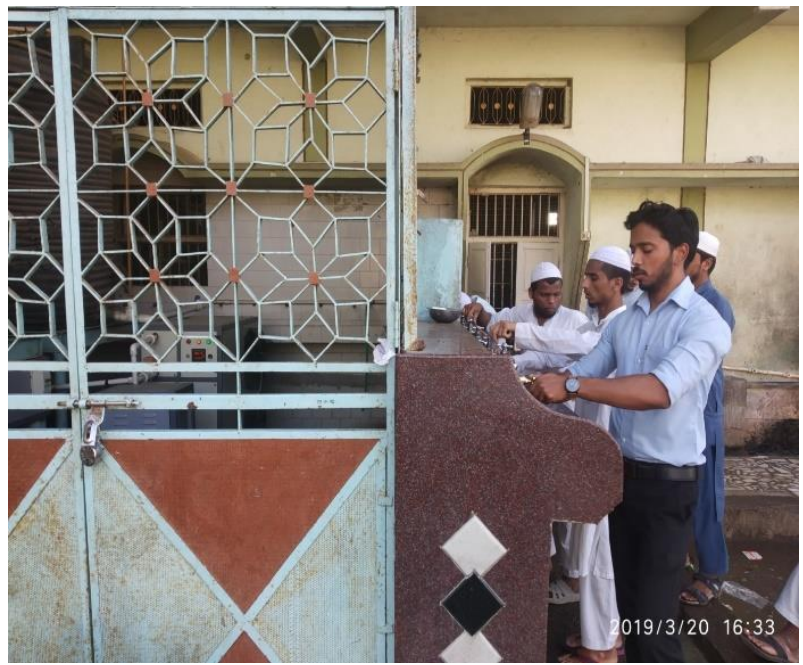

Fig-3. Jamia filter water

\section{METHODOLOGY}

$3.1 \mathrm{pH}$ : - $\mathrm{pH}$ is one of the most common analyses in water testing, is the standard measure of how acidic or alkaline a solution is. It is measure a scale from 014. $\mathrm{pH}$ is of 7 is neutral, $\mathrm{pH}$ is less than 7 is acidic and $\mathrm{pH}$ is more than 7 is basic.

3.2 Conductivity: - conductivity is measured by electric conductivity meter which is carried our solution electric conductivity used to quickly estimate the ionic or soluble salt concentration in water sample. The instrument is standardized with known values of conductance observed with KCL solution.

3.3 Turbidity: - Turbidity may be due to organic and inorganic constituents. Organic particulates may harbor micro-organism. Thus, turbid conditions may increase the possibility for bone disease.

3.4 Dissolved Oxygen: -: The amount of oxygen which is dissolved in water, such as river and lake. All living organisms depend upon oxygen to maintain the metabolic process that produce energy for growth and water quality index increase till dissolved oxygen value reaches to $100 \mathrm{mg} / \mathrm{lit}$. Above $100 \mathrm{mg} / \mathrm{lit}$, the water quality index decrease and the water quality becomes very poor. D.O is the most important indicator of the health of water bodies and its 
capacity to support balanced aquatic ecosystem of plants and animals

\subsection{Chemical Oxygen Demand: - The standard} method for indirect measurement of the amount of pollution in a sample of water. The chemical oxygen demand test produce is based on the of the chemical decomposition of organic and inorganic contaminants, dissolve in water. If excess organic is introducing to the system, there is potential for complete depletion of dissolved oxygen. Without oxygen the entire aquatic community is threatened. The only organism present will be air- breathing insects and anaerobic bacteria.

3.6 Biological Oxygen Demand: - B.O.D is a measure of organic pollution to both waste and surface water. High B.O.D is an indication of poor water quality.

BOD is a measure of organic material contamination in water, expressed in $\mathrm{mg} / \mathrm{l}$. BOD is the amount of dissolved oxygen required for the bio chemical decomposition of organic compounds and the oxidation of certain inorganic materials. Typically, the test for BOD is conducted over a five days' period.

3.7 Hardness: - Hardness is defined as the sum of calcium and magnesium hardness in $\mathrm{mg} / \mathrm{l}$ as $\mathrm{CaCO} 3$. As per IS: 10500-2012 desirable limit and permissible limit for hardness lies between 200-600 mg/l respectively. The effect of hardness is scale in utensils and hot water system in boilers. High concentration of hardness may Couse the problem of heart disease and kidney stones.

\subsection{Alkalinity: - Alkalinity is a chemical} measurement of waters ability to neutralize acid. Alkalinity is also a measure of a water buffering capacity or its ability to resist changes in $\mathrm{pH}$ upon the addition of acids or bases. Alkalinity of natural water is due to primarily to the presents of weak acids salts, although strong bases may also contribute in the extreme environment. Other salts of week acids such as borate, silicates, ammonia, phosphate and organic bases from natural organic matter may be present in small amount. It is measured by titrations with standardized acid to a $\mathrm{pH}$ value of 4.5 and is express commonly as milligrams per liter as calcium carbonate. Commonly occurring materials in water that increase alkalinity are carbonates bicarbonates, hydroxides. Lime stone bad rock and thick deposits of glacial till are good sources of carbonate buffering, lakes within such areas are usually well buffered.

3.9 Alum dose or Co-agulants: - Co-agulants are used in water treatments plants to remove natural suspended and colloidal mater and it is also remove that material which do not settle in plan sedimentation. Alum is the most widely used coagulant. When alum solution added to water the molecules dissociate to yield $\mathrm{SO}_{4}{ }^{2-}$ and $\mathrm{Al}^{3+}$. The positive species combine with negatively charged colloidal to neutralize part of the charge on the colloidal particle thus, agglomeration takes place. Coagulants is a quite complex phenomenon and the coagulents should be distributed uniformly throughout the solution.

Jar test is simple device used to determine this optimum co-agulant thus required. It is also expressed in $\mathrm{mg} / \mathrm{lit}$.

3.10 Residual chorine: - All type of natural and raw water contains chlorides. Its comes from activities carried out in agricultural area. The chlorine demand is satisfied upon initial dosing, chlorine reacts with any organic matter in water the amount of chlorine used in this reactions is known as the chlorine demand of the water. When the chlorine demand of the water is satisfied, some portion of the remaining chlorine reacts with nitrogen in the water to from compounds known as chloramines. Nitrogencontaining compounds may result from decaying organic matter in raw water secured for drinking water treatment. In swimming pool, swimmers add nitrogen-containing compound to the water in the form of substance such as urine and perspiration. 
Chloramines may impart a chemical odor to water, which is sometimes in accurately described as a "chlorine" odor. The chlorine that combines chemically with nitrogen-containing compounds is known as "combined chlorine".

3.11 Total Solids: - Total dissolved solids is a measure of the suspended and dissolved solids in water. Total solids are directly related to the purity if water and the quality of water purification system and effects everything that consumes, lives in, or uses water, whether organic or inorganic, whether for better or worse. Common inorganic salts that can be found in water include calcium, magnesium, potassium and sodium which are cations and carbonates, nitrates bicarbonates, chlorides and sulphates which are anions. The settling of suspended solid from turbid waters threatens benthic aquatic communities. Deposited particles may obscure sources of food, habitat, hiding places and nesting sites. Most aquatic insects will simply draft with the current out of the affected area. Increase sediment may impact plant communities. Primary production will decline because of a deduction in light penetration. Sediment may damage plants by burial, scouring and abrasion.

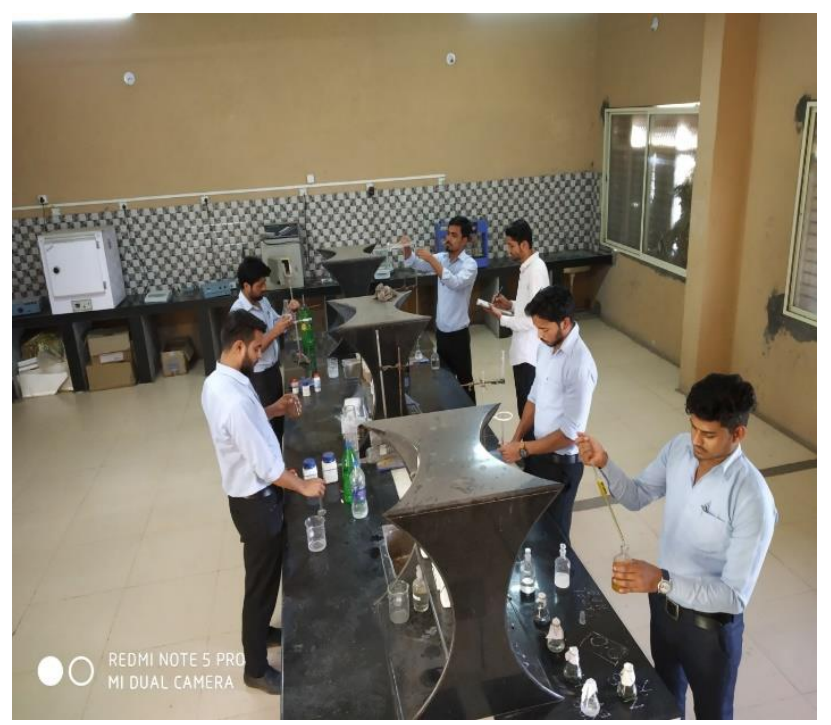

Fig-4. To conducted different titration methods

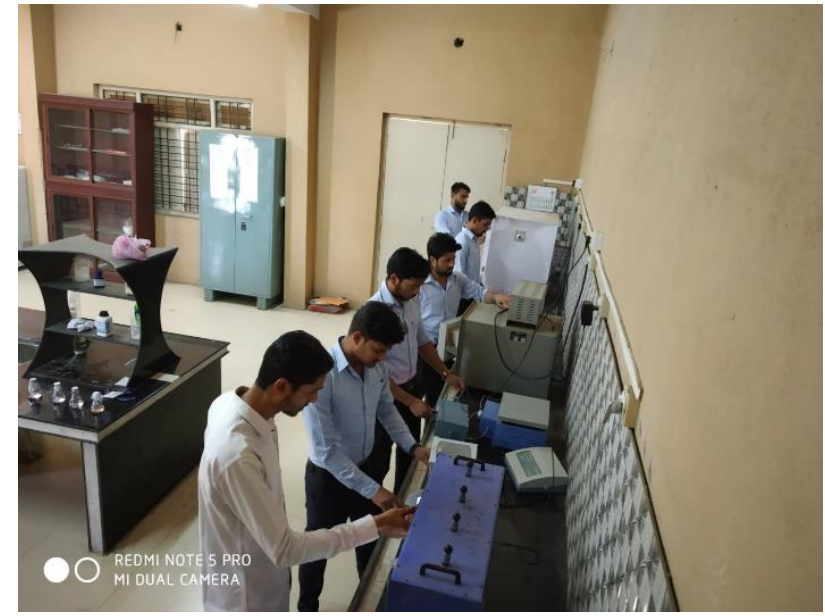

Fig-5. To find out the different parameters

\section{DISCUSSION}

During the study period various physio-chemical municipal supplied water quality parameters like $\mathrm{pH}$, turbidity, conductivity, TDS, alkalinity, total hardness, residual chlorine, D.O, B.O.D, COD, colour, odour, taste are conducted.

According to above conducted parameters we clarify that some parameters are under the acceptable limit and some are not, due to which many problems are faces by the consumers like kidney stones, cholera, diabetes, blood pressure, cancer, diarrhea, malaria, dengue etc. These are the major factors which are directly harmful affected to the aquatic life or human body.

As per the study the average $\mathrm{pH}$ of different sampling site was 7.51 which are within acceptable limit. Highest value (8.31) of $\mathrm{pH}$ was found at the Sample2.

Turbidity is essential for measure because if turbidity is high then it is block filters and stop them working effectively. As per our study we see that turbidity of all samples are under the acceptable limit.

TDS refers to matter suspended or dissolved in water or waste water with high content inferior and may be polluted. In study it was found that the TDS of akkalkuwa region average TDS is $327 \mathrm{mg} /$ lit. But 
according to our study TDS of sample $1 \& 2$ is high from desirable limit.

Similarly, we see that the value of hardness and residual chlorine are excess in $1 \& 2$ as per WHO limit. Also saw that Dissolved oxygen is under the desirable limit or under the WHO limit, but we see that after 5 days' incubation at $20^{\circ} \mathrm{C}$ biological oxygen demand is very high $(2.8 \mathrm{mg} / \mathrm{lit}$ ) for sample-2 (municipal corporation) while WHO limit say that it is not exceed $1.2 \mathrm{mg} /$ lit.

Alkalinity range of water in different samples in around Akkalkuwa municipal supply water where found average $32.34 \mathrm{mg} / \mathrm{lit}$ which is under the permissible limit.

\section{CONCLUSION}

The effects of water pollution are not only devastating to people, but also to animals, fish, and birds also destroy aquatic life and reduces its reproductive ability.

Polluted water is unsuitable for drinking, recreation, agriculture, and industry. It diminishes the aesthetic quality of lakes and rivers. Eventually, it is a hazard to human health.

The present review paper undertaken to account to bring an acute awareness among the people about the quality of water.

The individual and the community can help minimize water pollution by simple housekeeping and management practices the amount of waste generated can be minimized.

The problem associated with waste water reuse arise from its lack for treatment.

The challenge thus it to find such low-cost, lowteach, users friendly methods, which on one hand avoid treating us sustains waste water depend living hoods and on the other hand protect degradation of our valuable natural resources.
The use of constructed wetlands is now being recognized as an efficient technology for waste water treatment. Compare to the conventional treatment system, constructed wetlands need lesser material and energy, are easily obtained have no sludge disposal problems and can be maintain by untrained personnel.

Further these systems have lower construction, maintenance and operating costs as this are driven by natural energy of sun, wind, soil, micro-organisms, lands and animals.

Hence, for planned, strategic, safe and sustainable use for waste water there seems to be a need for policy discussion and coherent programs encompassing lowcost decentralized waste water treatment technologies.

So in this project, various taste will be conducted on water and compare it with I.S \& B.I.S standard. Until now no one has compare the ground water quality on the basis of various zones. Therefore, there is the potential for this project.

\section{REFERENCES}

[1]. Municipal Corporation of Akkalkuwa Dist Nandurbar.

[2]. National rural drinking water programme guide line (2013), Ministry of drinking water and sanitation, Government of India.

[3]. Uniform drinking water quality monitoring protocol (2013), Ministry of drinking water and sanitation, Government of India.

[4]. International journal of chemical studies (2015).

[5]. International journal of engineering science invention research and development (2015).

[6]. Mishra S.G. and D. Mani, Soil Pollution. Efficient offset Printer ABC, New Delhi, India,1991.

[7]. International journal of chemical studies 2015; 3(4): 24-28. 
[8]. Journal of global bio-sciences volume 4, no.5,2015, pp.2375-2379.

[9]. APHA (1998): Standard method for examination of water and waste water.

[10]. Patnaik, K.N Satya Narayana, S.Y. and Rout. S.P. (2002). A case study on water pollution from major causes in environment PP 2032011.

\section{Cite this article as :}

Shaikh Ibrahim, Seraj Alam, Margub Alam, Faisal Ahmad, Saiyad M Asif, Syed Sarfraz Shahid, Umarfarook H Momin, "A Review on Ground Water Quality Assessment of Akkalkuwa Region, Nandurbar (Maharashtra)", International Journal of Scientific Research in Science and Technology (IJSRST), Online ISSN : 2395-602X, Print ISSN : 2395-6011, Volume 6 Issue 2, pp. 573-579, MarchApril 2019. Available at doi :

https://doi.org/10.32628/IJSRST1962117

Journal URL : http://ijsrst.com/IJSRST1962117 